\title{
Toda literatura es histórica: Dr. Oswaldo Estrada
}

\author{
Paulina Ruelas, Oswaldo Estrada
}

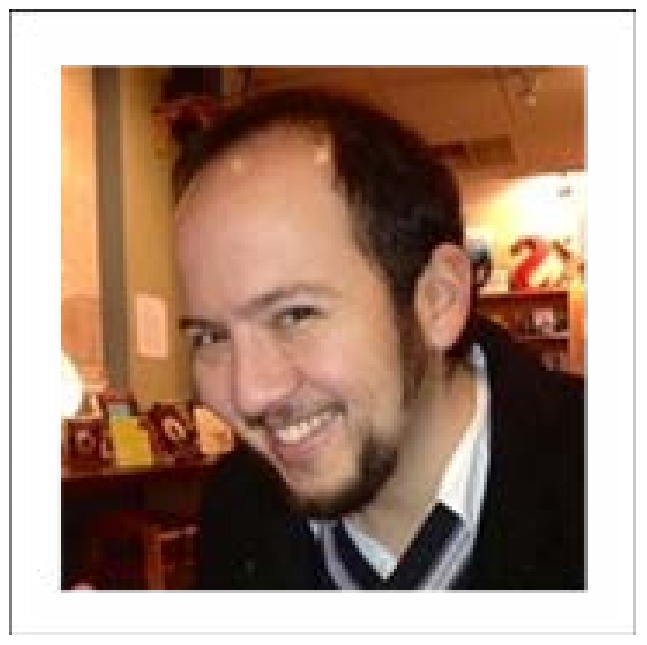

E1 Dr. Oswaldo Estrada es profesor en la Universidad de Carolina del Norte en Chapel Hill y editor de Romance Notes. Al entrevistarlo me conmovió su sencillez y su facilidad de palabra: hablar con él es como hablar con un viejo amigo al que no habías visto hace mucho tiempo. En la siguiente entrevista el especialista en literatura novohispana y mexicana nos cuenta cómo descubrió su vocación y describe su trayectoria al tiempo que habla sobre sus proyectos más próximos.

El profesor Estrada empieza a contarnos cómo empezó su interés hacia la literatura y qué fue lo que le confirmó su vocación como escritor e investigador. "Todo empezó cuando fui a la Universidad de California pensando en estudiar algo que tuviera que ver con la medicina porque eso es lo que me dijeron en mi casa desde chiquito, que iba a estudiar para ser médico. Y empecé a tomar las clases que aquí se conoce como "pre-med". Me la pasaba muy mal porque no me interesaban esas clases, pero yo tenía que ser médico. Entonces tomé una clase de español porque quería darme el gusto y también porque había una gran parte de mí en ello, un trozo de mi vida que se había quedado olvidado".

Nos cuenta que nació en los EE.UU. pero creció en Perú y luego regresó a los 14 años a los EE.UU. y no tomó ninguna clase de español hasta los 18 ó 19 años. "Cuando me inscribí en una clase de español y escuché a la maestra hablar en español, yo la miré y dije "esto es lo que quiero hacer en la vida". Me encantó tanto que en mis clases de química me llevaba mis novelas a clase. Mientras todos estaban en clases con las 
gráficas, yo estaba sentado atrás leyendo mi novela, y después de varias clases de hacer eso, me di cuenta que lo mío era la literatura. Me gustaba mucho leer y escribir y me costaba mucho realizar actividades para otras clases, como los problemas de matemáticas y de química; en cambio, era para mí un gusto sentarme a escribir sobre una novela, sobre un cuento, me encantaba ir a mis clases de español y descubrí que esa era mi vocación".

Al descubrir su vocación, el Dr. Estrada nos dice cómo comenzó su carrera y llegó a ser profesor en la Universidad de Carolina del Norte: "Yo hice algo muy inusual, yo estudié toda mi carrera en la misma universidad. Me sentí muy en casa y muy a gusto con los profesores y gracias a que por ellos descubrí lo que verdaderamente quería hacer, decidí quedarme para la maestría y el doctorado. Conseguí mi primer trabajo en el estado de Washington cerca de Seattle en un colegio y estuve ahí por tres años, lo disfruté muchísimo. Aprendí muchísimo del oficio de ser profesor y me identifiqué mucho con estos estudiantes que llegaron como yo. De allí surgió la oportunidad de mudarme a una institución en Carolina del Norte y desde el primer momento que me entrevisté sentí que éste podría ser un lugar para mí. Llevo 8 años trabajando en la Universidad de Carolina del Norte y estoy contento con mi trabajo y con mis estudiantes".

E1 Dr. Estrada se enfoca primordialmente en las literaturas de México y Perú pero, ¿por qué el enfoque en esas áreas? Lo mas lógico, nos cuenta el Dr. Estrada, era que estudiara literatura peruana del siglo XX, pero nos cuenta cómo empezó su interés en la literatura mexicana: "Yo vine a este país, a California, a los 14 años y a los 14 años crucé la frontera a México con mis familiares simplemente para conocer y me enamoré de México; lo digo con toda la honestidad del mundo. Perú me queda tan lejos, y tan lejos mi familia, y tan lejos del mundo que yo había dejado atrás, que México era lo que más se parecía a mi mundo. Sentir que estaba en una parte de lo que era mi mundo, fue como redescubrir una parte que podía ser mía. Yo siempre digo, "nací en Estados Unidos y mis padres fueron a Perú y Perú fue mi primera patria, pero México ha sido y seguirá siendo mi segunda patria por elección". Pensar en México es pensar en mi casa y pensar en Perú es pensar en esa otra patria en donde viví los primeros 14 años de mi vida".

E1 Dr. Estrada tiene varios libros publicados, entre ellos La imaginación novelesca. Bernal Díaz entre géneros y épocas (2009), Cristina Rivera Garza. Ningun critico cuenta con esto... (2010) y Colonial Itineraries of Contemporary México. Literary and Cultural Inquiries (2014). E1 Dr. Estrada habla un poco sobre el libro La imaginación novelesca. Bernal Díaz entre géneros y épocas, y nos explica qué quería dar a conocer con esa investigación: "Me gustaban muchas cosas, me gustaba la literatura colonial, la literatura del siglo de oro, me gustaba Sor Juana Inés de la cruz, pero también me gusta Carlos Fuentes, me gustaba de todo y leí que Carlos Fuentes había dicho, en un libro, que para él Bernal Díaz era el primer novelista porque nos ponía frente a nosotros un mundo inacabado, un mundo en proceso de ser, y que más que una crónica de la conquista, era verdaderamente nuestra primera novela. Bernal Díaz, que fue un soldado que participó en la conquista de México al lado de Hernán Cortés, comienza a escribir su manuscrito y nos cuenta una historia fascinante. Comencé a leer Historia verdadera y me enamoré de ese arte de narrar. Al mismo tiempo que iba leyendo la crónica de Bernal Díaz, seguí yo mis estudios sobre la novela contemporánea, sobre la teoría de la novela, y lo que decidí hacer con esta investigación fue estudiar los elementos novelescos de la crónica de Bernal Díaz. La crónica de Bernal Díaz no es una novela. Sin embargo, sí tiene elementos novelescos como 
la caracterización de los personajes, el manejo magistral del tiempo y el espacio de la creación del suspenso que Bernal Díaz crea de un lado a otro. Eso fue lo que yo hice a través de varios capítulos. Estudié estos elementos que yo considero novelescos y la razón que hacen que esta crónica sea mucho más duradera que otras. En el último capítulo quería yo ver cómo distintos autores contemporáneos habían vuelto, de una u otra forma, a reescribir la crónica de Bernal Díaz con trozos, fragmentos de su larga crónica dentro de sus propias ficciones. Te puedes dar cuenta cómo hacia el final de ese libro yo ya me había orientando hacia lo que hago más ahora, es decir, a cuestiones de rescritura histórica, memoria histórica, representaciones del trauma memorial, etc".

El enfoque de estudio del Dr. Estrada se basa en el efecto estético de rescribir la historia, la formación y transgresión del género, y la construcción de la identidad en los siglos XX y XXI. El profesor Estrada nos explica la relación entre literatura e historia y qué es lo que la literatura nos puede decir de la historia: "Yo creo que toda literatura es histórica. Creo que nosotros, en América Latina, vivimos constantemente palpando nuestra colonialidad, es decir, todo lo que nos da una condición colonial. Habiendo crecido en un lugar tan colonial como en Lima, Perú, y estando tan cerca de México, que también está llena de un colonialismo que se puede palpar en cada esquina del país, para mí tiene mucho sentido estudiar esta parte colonial no solamente porque responde a preguntas que tenemos ahora en el presente como quiénes somos, cómo hemos llegado y toda esta serie de prejuicios étnicos, de clase y de género, pero porque de alguna manera en América Latina, aunque parece que el tiempo es lineal, realmente estamos volviendo hacia atrás constantemente en una serie de círculos que vuelven hacia el pasado para tratar de interpretar lo que es el presente; es como avanzar un paso pero regresando dos".

En relación con su libro Ser mujer y estar presente. Disidencias de género en la literatura mexicana contemporánea (2014), el Dr. Estrada nos dice cuáles son las ideas que subyacen detrás de ese volumen y qué significa realizar estudios de género desde la literatura: "Yo comencé a trabajar en este libro desde hace mucho tiempo y había empezado a publicar algunas cosas sobre Elena Poniatowska y Rosario Castellanos, y después hice un libro colectivo sobre Cristina Rivera Garza y publiqué algún articulo sobre Rosa Beltrán. Un día, centrándome, vi que tenían muchos rasgos en común, es decir, que todas estas mujeres el afán de definirse cómo intelectuales dentro de un panorama bastante machista mexicano del siglo XX y cómo todas ellas trataban de realizar transgresiones dentro de su literatura con personajes femeninos muy fuertes y personajes femeninos que se rebelan contra la norma. En el libro lo que hago es observar estos distintos momentos de transgresión, qué es lo que hace Rosario Castellanos por ejemplo en su poesía, o lo que hace Elena Poniatowska cuando también le da voz a las mujeres. De esto trata el libro: de cómo distintas mujeres mexicanas nacidas todas a lo largo del siglo XX realizan distintos actos de trasgresión en su escritura y cómo muchas de ellas consciente o inconscientemente también dialogan con la historia. Hay varias vertientes que se van juntando en este libro y el título Ser mujer y estar presente tiene que ver mucho con esto de ser mujer escritora y hacer un espacio dentro de México a través de la literatura y luchar por ti y por otras personas que tratan de definirse dentro de un medio bastante misógino".

A pesar de todos los proyectos, trabajos e investigaciones que el Dr. Estrada ha hecho hasta ahora, hay uno en particular al que le tiene mucho afecto y que puede decir que ha sido su mejor trabajo hasta hoy: 
"Podría contestar con la respuesta que todos dan: "lo que acabo de escribir es lo mejor que he escrito en la vida". Sin embargo, hay una parte de cierto en eso. Yo creo que siempre le pongo alma, corazón y vida a todo lo que estoy escribiendo y siempre me he sentido muy contento con lo que he escrito en el momento. Te puedo decir que le tengo un cariño muy grande al libro Ser mujer y estar presente porque es un libro que en muchos sentidos le debo a las grandes mujeres que han estado presentes en mi vida, y hablo de mi madre en primer lugar, que me crió sola a mí y a mi hermano, y que fue una mujer muy luchadora, una mujer muy fuerte, y que sigue siéndolo. Cuando escribí en el libro pensaba en mi abuela que también fue y sigue siendo una mujer muy fuerte a sus noventa años, que estudió para ser maestra, que se hizo sola realmente y salió adelante. También pienso en mi propia esposa, a quien le dedico el libro, porque uno nunca trabaja solo, uno siempre tiene a maestros, a guías, a gente, a amigos, y yo he tenido la suerte de tener a mujeres muy fuertes como ejemplos en mi vida anterior y ahora".

Sabiendo que ningún trabajo es fácil y que todo toma esfuerzo, el Dr. Estrada nos cuenta del trabajo más difícil que ha hecho hasta ahora y por que ha sido el más difícil: "El trabajo más difícil que he hecho ha sido un capitulo del libro que escribí sobre el Subcomandante Marcos por varias razones. Fue difícil para mí internarme en un tipo de literatura que no conocía, es decir, yo estoy muy acostumbrado a leer cuentos, novelas y crónicas, pero leer al Subcomandante Marcos fue como entrar a un mundo completamente distinto al mío. Sin embargo, a final de cuentas y después de leer varios de sus comunicados, manifiestos y cartas muy políticas, encontré algo que se parecía a lo mío. Fue un gran descubrimiento para mí como crítico, como académico, y después de mucho estudio y después de mucho trabajo, me quedé bastante contento con el producto final".

A pesar de todo el éxito que el Dr. Estrada tiene hasta ahora, su pasión por la literatura continúa y nos cuenta lo que podemos esperar de él, su próxima meta. "Estoy terminando un libro en inglés que se llama "Bad Habits. Historical Women in Postcolonial México", y estudia representaciones históricas de, por ejemplo, la Malinche, Sor Juana, etc., en la literatura de hoy. Seguramente que en un par de años se publicará, pero antes salió un libro que se titula Senderos de violencia. Latinoamérica y sus narrativas armadas (2015) y este es un libro colectivo que trata sobre distintas representaciones de la violencia en América Latina. Por ejemplo, la violencia en México, la violencia fronteriza que hemos tenido en los últimos años, las representaciones de la violencia en el Perú durante los años 80 y 90, representaciones de la violencia de la Guerra Sucia en Argentina, etc. Son varios investigadores y varios escritores; yo también tengo un capítulo sobre las representaciones de la violencia y soy el editor del libro".

En todo trabajo y estudio se aprende y siempre hay algo que nos llama la atención o bien nos impresiona e impacta de una forma u otra. Al respecto, el Dr. Estrada dice: "Yo sigo pensando que la vida supera a la literatura; lo pienso de todo corazón. A veces uno encuentra textos literarios en los que uno puede encontrar cierta paz, cierto estado de destrucción, nota que estoy hablando de dos polos opuestos, porque uno necesita sentirse identificado. Muchas veces uno necesita saber que esto que te ha pasado a ti también le pasó a otra persona y que algún escritor o escritora decidió llevarlo a cabo".

Cambiando un poco de tema, el Dr. Estrada nos da su opinión sobre el impacto de las nuevas tecnologías en la literatura latinoamericana y el público en general. No sabremos lo que pasará con los libros impresos 
y cuáles serán los nuevos avances tecnológicos, pero el Dr. Estrada nos da su opinión de lo que será el destino del libro frente a las nuevas tecnologías como el Internet: "Yo vengo de una generación que no es tecnológica y, por supuesto, cuando yo era estudiante solamente existía el libro. Ya desde entonces me acuerdo que muchas personas se revelaban contra las nuevas tecnologías. Sin embargo, yo creo que el libro sigue y seguirá existiendo en el futuro. Quizás no se publicarán tantos libros, tantas ediciones en papel, pero habrá mucha gente, como yo, que seguirá leyendo los libros porque nos gusta, porque nos gusta tocar las páginas, leer los libros y dejarlos en la mesa de noche. Pero me ha sorprendido ver que, por ejemplo, los niños en los aviones y la gente mayor van leyendo del Kindle. Yo soy editor de la revista Romance Notes y me sorprende la cantidad de artículos que ahora nos llegan y que yo reviso, y al revisar la bibliografía veo que están citando de Kindle. Sin embargo, honestamente, yo no lo veo como algo negativo; pienso que es el camino por donde se está moviendo el mundo y nosotros también tenemos que agarrarle la mano a la tecnología. Yo no creo que el libro impreso vaya a desaparecer".

El Dr. Estrada cuenta que aunque no siempre ha sido fácil, siempre ha tenido a gente que le ha apoyado y ayudado a lo largo de su carrera y nos comparte el mejor consejo que a ha recibido. "El mejor consejo que he recibido en la vida es que uno tiene que ser audaz, valiente y arriesgado. Es decir, si tú tienes una meta en la vida y crees que podría ser difícil pero no sabes, que te gustaría sacar un doctorado pero no tienes dinero, yo creo que debes apostar por eso y seguir tu corazón. Yo estoy en esta carrera porque tuve a gente que me orientó y me dijo: "tú vales para esto", "tú puedes hacerte un espacio pequeñito dentro de este campo literario". A veces no fue fácil porque te puedes imaginar que uno como estudiante tiene distintos obstáculos, distintas necesidades económicas, etc., pero a fin de cuentas aquí estoy. Es y fue un buen consejo porque cuando uno cree y tiene fe en algo, debe seguirlo contra viento y marea".

Por último, el Dr. Estrada dijo qué recomendaciones daría a un aspirante escritor o investigador de estudios literarios: "Yo creo que todo es paso a paso y que mi mejor consejo para los estudiantes es que piensen que todo son pasos en la carrera, poquito a poco. No significa que ese artículo que estás escribiendo ahora va a ser el mejor artículo de tu vida porque la escritura también es un oficio y cuanto más escribes mejor te vuelves en el oficio de escribir. Trata de hacer todo paso a paso, no te preocupes pensando cómo conseguir una maestría, un doctorado, o cómo publicar un articulo, pues todo es poquito a poco. También es importante buscar ayuda de la gente alrededor. Siempre hay alguien ansioso de ayudar a otra persona: uno nunca llega solo a ninguna parte".

Como podemos ver, la trayectoria del Dr. Estrada continúa y, aunque no siempre ha sido fácil, su amor hacia la literatura sigue y esa pasión se puede ver por medio de su trabajo y el cariño que le tiene a sus estudiantes. El Dr. Estrada ha perseverado y ha logrado con gran esfuerzo, dedicación y apoyo lo que a lo mejor nunca pensó que fuese a lograr. Su historia y experiencia es un ejemplo para todos. 